\title{
Magnetic Anomalies in the Western Part of the North Anatolian Fault Zone and Their Implications for Active Fault Structure
}

\author{
A. Mete IşiKara ${ }^{1)}$, Y. Honkura ${ }^{2)}$, N. Watanabe ${ }^{2)}$, \\ N. ORBAY ${ }^{1)}$, D. KOLÇAK ${ }^{1)}$, N. OHSHIMAN ${ }^{2)}$, \\ O. GUNDOĞDU ${ }^{1)}$, and H. TANAKA ${ }^{2)}$ \\ 1) Department of Geophysics, University of Istanbul, Istanbul, Turkey \\ 2) Department of Applied Physics, Tokyo Institute of Technology, Tokyo, Japan
}

(Received October 29, 1984; Revised November 27, 1984)

In 1981 and 1982 intensive observations of the geomagnetic field were carried out in a possible seismic gap region in the western part of the North Anatolian Fault Zone to trace on active fault and also to accumulate geomagnetic data for earthquake prediction research. The data of magnetic anomalies obtained from profile measurements across the fault were interpreted to reveal an anomalous magnetic structure associated with the active fault. In order to confirm our results thus derived in the Iznik-Mekece area, similar observations were also made at Ismetpaşa where fault traces are well known as well as creep for the North Anatolian Fault Zone.

It is concluded that highly magnetized dike-like bodies exist extensively along active fault lines in the North Anatolian Fault Zone. This characteristic feature can be utilized for studies of active fault location and also for tectonomagnetic studies.

\section{Introduction}

The North Anatolian Fault Zone is an area of extremely high earthquake risk. Large and destructive earthquakes have occurred during the last decades. A clearly defined two-directional migration of earthquake epicenters from a central region, located at about $39^{\circ}$ in the east longitude, and the existence of the two areas, suspected as seismic gaps of the first kind [one is between $29^{\circ}$ and $30^{\circ} \mathrm{E}$ in longitudes in the west (ToKsöz et al., 1979)], are two of the outstanding features of the zone.

Hence, the chance "to capture an earthquake" by carrying out earthquake prediction research by multidisciplinary observations at properly selected observation sites along the fault seems rather promising in the case of the North Anatolian Fault Zone.

Since one of the effective means of earthquake prediction is to carry out

* Now at Department of Earth Sciences, College of Humanities and Sciences, Nihon University, Tokyo, Japan. 
magnetic research to detect possible local changes in the geomagnetic field relating to tectonic activities within the crust, we initiated magnetic observations to study an anomalous magnetic structure along the fault and to select sites for repeated and continuous magnetic measurements at the possible seismic gap region in the western part of the North Anatolian Fault Zone (Here, it is necessary to mention that we also made resistivity measurements as described in our previous paper (HonkURA et al., 1985); the details will also be presented by HonkURA et al. (in preparation)).

In 1981 and 1982, magnetic measurements were made at some profiles perpendicular to the active fault line in the Iznik-Mekece region, and in order to confirm the results of our observations here, we also selected the Ismetpaşa area, where fault traces are well established, for magnetic measurements. In these area typical magnetic anomalies were observed and it has been speculated that such magnetic anomalies may be caused by strongly magnetized dike-like bodies which would be intruded from some depth of the earth.

The purpose of this paper is to search for models which can account for the observed magnetic anomalies so as to investigate subsurface structure of active faults in the observation area.

\section{Some Characteristics of the Observation Sites}

Several aspects of the North Anatolian Fault Zone including our observation sites have been discussed as a whole by ŞENGÖR et al. (1982) and SoYSAL et al. (1982). Also, SipAHIOĞLU and GÜNDOĞDU (1982) have shown that there are two seismically active areas in the western part of the zone where large earthquakes also occurred in the past. One of them is an area southeast of Istanbul as is seen in Fig. 1. Our observation area would be located within this seismically active area.

From the distribution of earthquake epicenters in the Izinik-Mekece region, it is claimed that the area has been highly active during recent years and there is a good correlation between epicenters and active faults, as noticed in Fig. 2. In addition, Sipahioğlu and Matsuda (in preparation) have provided evidences showing the existence of an active fault running through the city of Iznik and the town of Mekece. This fault may be called the Iznik-Mekece fault and is shown by a solid line in Fig. 2.

The Ismetpasa area is known as a creeping segment of the North Anatolian Fault Zone and the fault traces are well established, as mentioned before. Since the detailed maps of our observation sites are given by HONKURA et al. (1985), we will not enter into further details here.

\section{The Method of Calculation}

The observed magnetic anomalies suggest a dike-like magnetic source and hence we attempt to interpret the magnetic anomalies by using dike models. In this respect, a method has been proposed by TELFORD et al. (1976) to calculate vertical 


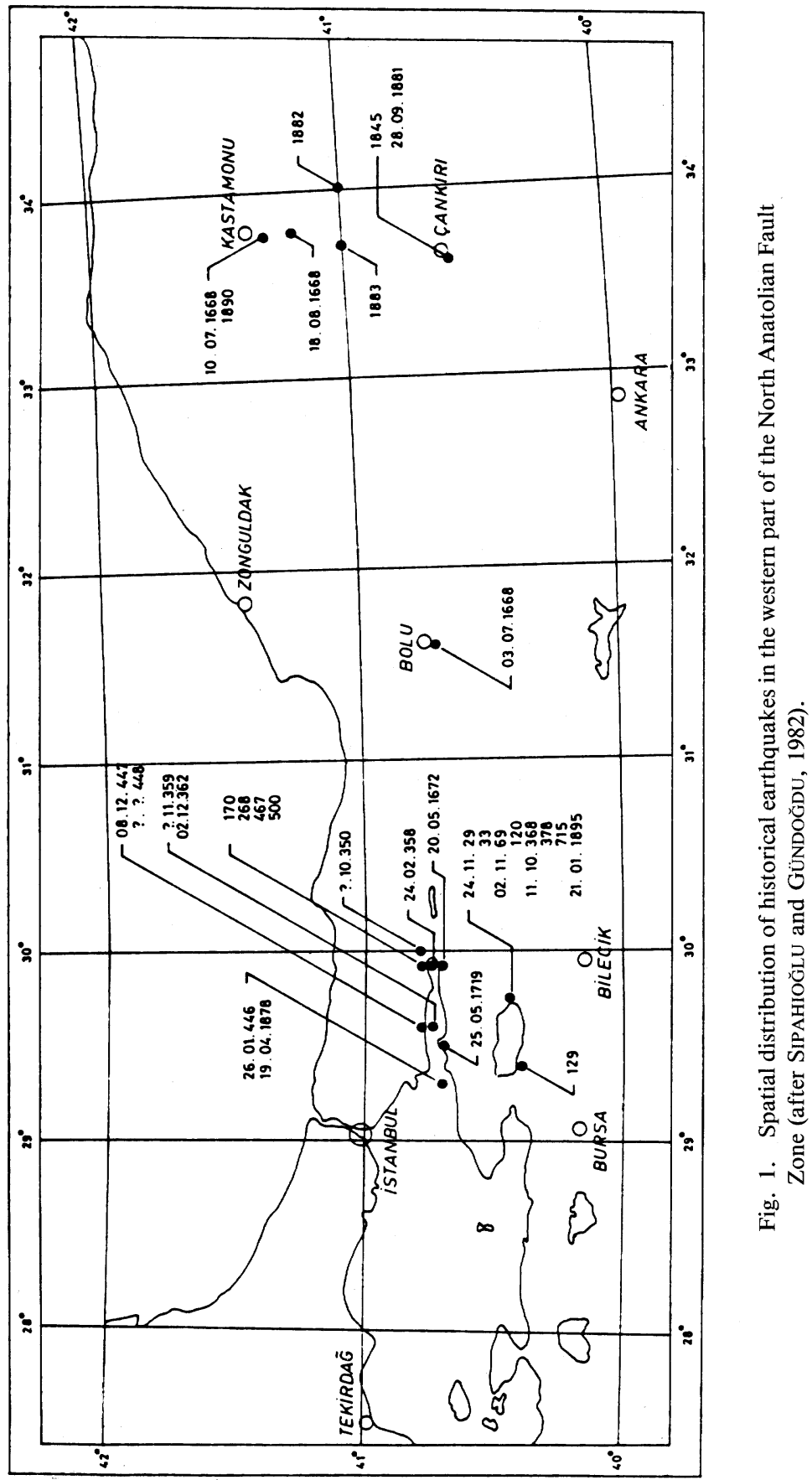




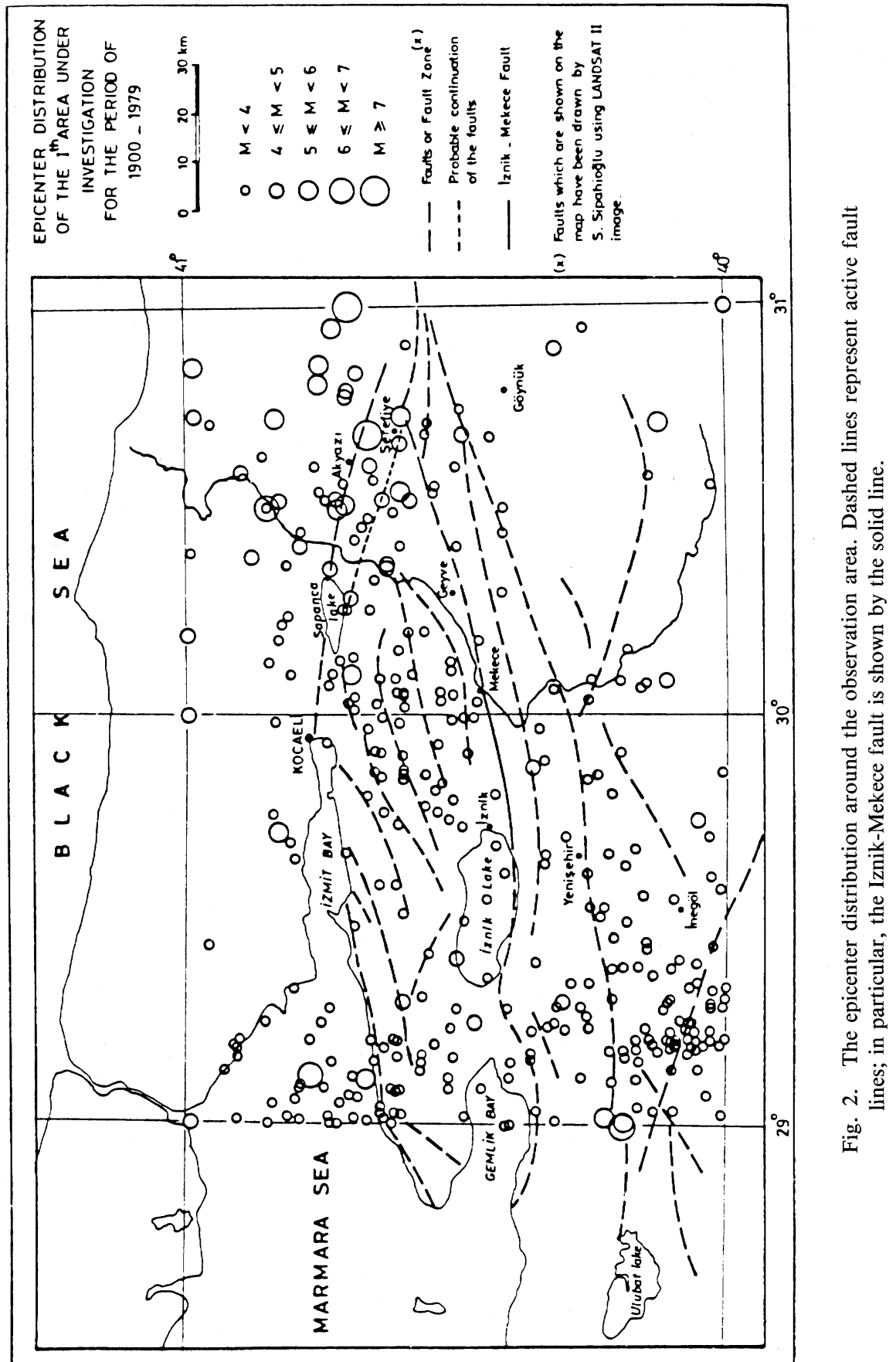


and horizontal field anomalies for a two-dimensional dike as shown in Fig. 3. On the basis of such a method, WoN (1981) put forward an inversion procedure for the determination of unknown parameters $\xi_{1}, \ldots, \xi_{5}$ as shown in Fig. 3 and $\xi_{6}$ as will be explained in the below.
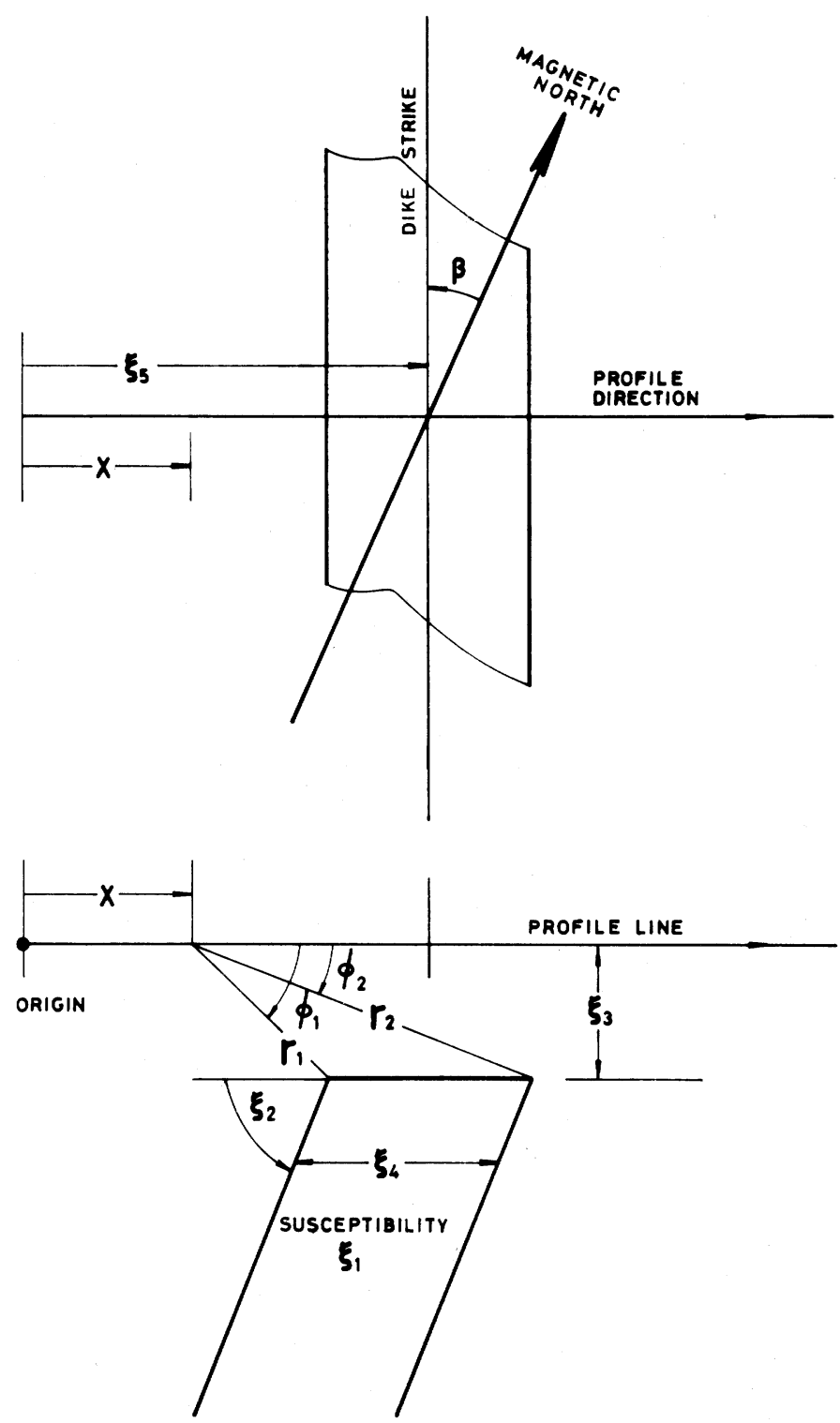

Fig. 3. Geometry and nomenclature of a dipping dike. 
These unkown parameters are

$$
\begin{aligned}
& \xi_{1}=\text { magnetic susceptibility } \\
& \xi_{2}=\text { dip angle, } \\
& \xi_{3}=\text { depth to the top of dike, } \\
& \xi_{4}=\text { thickness, } \\
& \xi_{5}=\text { horizontal location. }
\end{aligned}
$$

In addition, the normal value of the total intensity at an observation point is not usually known; hence it is represented by an unknown parameter $\xi_{6}$.

In the following, we will briefly review the inversion procedure. If we change $\xi_{i}(i=1,2, \ldots, 6)$ by small amount $\Delta \xi_{i}$, a change in $f$ (total intensity anomaly) is given by

$$
\Delta f=\sum_{i=1}^{6} \frac{\partial f}{\partial \xi_{i}} \Delta \xi_{i}
$$

For $N$ data points, $g_{i}(i=1,2, \ldots, N)$, we minimize the quantity

$$
S=\sum_{j=1}^{N}\left(f_{j}+\Delta f_{j}-g_{j}\right)^{2}
$$

with respect to $\Delta \xi_{i}$. Differentiating $S$ by $\Delta \xi_{i}$, we derive six simultaneous linear equations as

$$
\sum_{j} \sum_{i} \frac{\partial f_{j}}{\partial \xi_{i}} \frac{\partial f_{j}}{\partial \xi_{k}} \Delta \xi_{i}=\sum_{j}\left(g_{j}-f_{j}\right) \frac{\partial f_{j}}{\partial \xi_{k}} \quad(k=1,2, \ldots, 6) .
$$

If the above equations are solved for $\Delta \xi_{i}$, we can obtain an improved value $\Delta \xi_{i}^{\prime}$ such that

$$
\xi_{i}^{\prime}=\xi_{i}+\Delta \xi_{i}
$$

By replacing $\xi_{i}$ with $\xi_{i}^{\prime}$, this process can be repeated and if convergence is attained, the final values would be considered as solutions.

It turned out that this method could be applied successfully to the observed magnetic anomalies along the North Anatolian Fault Zone, as will be described in the following chapter.

4. The Results of Analysis for Subsurface Structure of the Faults

We used the following method to make calculations of magnetic anomalies due to dikes. First we created a dike vertical to the surface and derived an anomaly. Next, by changing the values of parameters for the dike, such as magnetic susceptibility, depth, thickness, and horizontal location as mentioned in the previous section, we obtained an approximate model. Finally, starting with this approximate model, we determined the best model of dike by using the method of inversion.

We regarded portions surrounding a dike as non-magnetized. We also assum- 
ed that the direction of magnetization is identical to that of the earth's field. We neglected the effect of undulation of topography, because it is generally flat in the present case; exceptionally we took into account its effect at Mekece. Inclination and declination of the earth's field are about 55 degrees and 5 degrees, respectively. First of all, the results obtained for the profiles in the Iznik-Mekece region are presented. The observation lines are shown in Fig. 4.

\subsection{Analysis of the magnetic anomaly at Mekece}

Figure 5 shows the observed data of geomagnetic total intensity (dots) along the line C-D at Mekece, where the strike of fault runs east-west. As is evident from Fig. 5, the magnetic anomaly amounts to about $500 \mathrm{nT}$.

First we created a dike of susceptibility $1.38 \times 10^{-3} \mathrm{emu} / \mathrm{cm}^{3}$, that is $1.73 \times 10^{-2}$ in SI, depth $100 \mathrm{~m}$, and thickness $800 \mathrm{~m}$. This model can roughly explain the observed magnetic anomaly as shown in Fig. 5 (shown by a continuous line). $\mathrm{Rms}$ error between results of observation and calculation is about $43 \mathrm{nT}$. The effect of topographic undulation is included in this calculation because altitude at point $\mathrm{D}$ is much higher than that of the flat region at point $\mathrm{C}$. The result of inversion is shown in Fig. 6. Rms error is reduced to about $20 \mathrm{nT}$, which is one half of that of the initial model. From this result, it is found that the dike is located at 110 $\mathrm{m}$ depth, its thickness is about $800 \mathrm{~m}$, its susceptibility is $1.5 \times 10^{-3} \mathrm{emu} / \mathrm{cm}^{3}$, and the dike dips to the north.

\subsection{Analysis for Çerkesli}

This observation line is represented by E-F in Fig. 4, about $4 \mathrm{~km}$ to the west of Mekece. We may expect a result similar to that of Mekece.

In Fig. 7, dots show observation data at Çerkesli. The total intensity ranges from $46250 \mathrm{nT}$ to $46750 \mathrm{nT}$. As an initial model, we considered a dike of $1000 \mathrm{~m}$ in thickness, $150 \mathrm{~m}$ in depth, and $1.38 \times 10^{-3} \mathrm{emu} / \mathrm{cm}^{3}$ in magnetic susceptibility, as shown in Fig. 7. This model can roughly explain the magnetic anomaly, and rms error is about $63 \mathrm{nT}$. Figure 8 shows the result of inversion. Rms error becomes 31 $\mathrm{nT}$. The thickness of the dike is $923 \mathrm{~m}$, its depth is $195 \mathrm{~m}$, and magnetic susceptibility is $1.63 \times 10^{-3} \mathrm{emu} / \mathrm{cm}^{3}$. The dike dips to the north, but the dip angle is smaller than that of the dike at Mekece. As expected, the result is similar to that for Mekece. The depth of the dike at Çerkesli is $85 \mathrm{~m}$ deeper than that at Mekece. If we consider the difference of $100 \mathrm{~m}$ in altitude between Çerkesli and Mekece, the top surface of dike can be regarded as located at nearly the same horizon.

In contrast to the magnetic anomaly mentioned above, there is a very local anomaly of short wavelength, as shown in Fig. 9(a). This anomaly is regarded as superposed on the long wavelength anomaly shown by the dotted line in Fig. 9(a). As shown in Fig. 9(b), this local magnetic anomaly can be explained by a thin and shallow dike which may be a branch from the main dike.

\subsection{Analysis for Çardak}




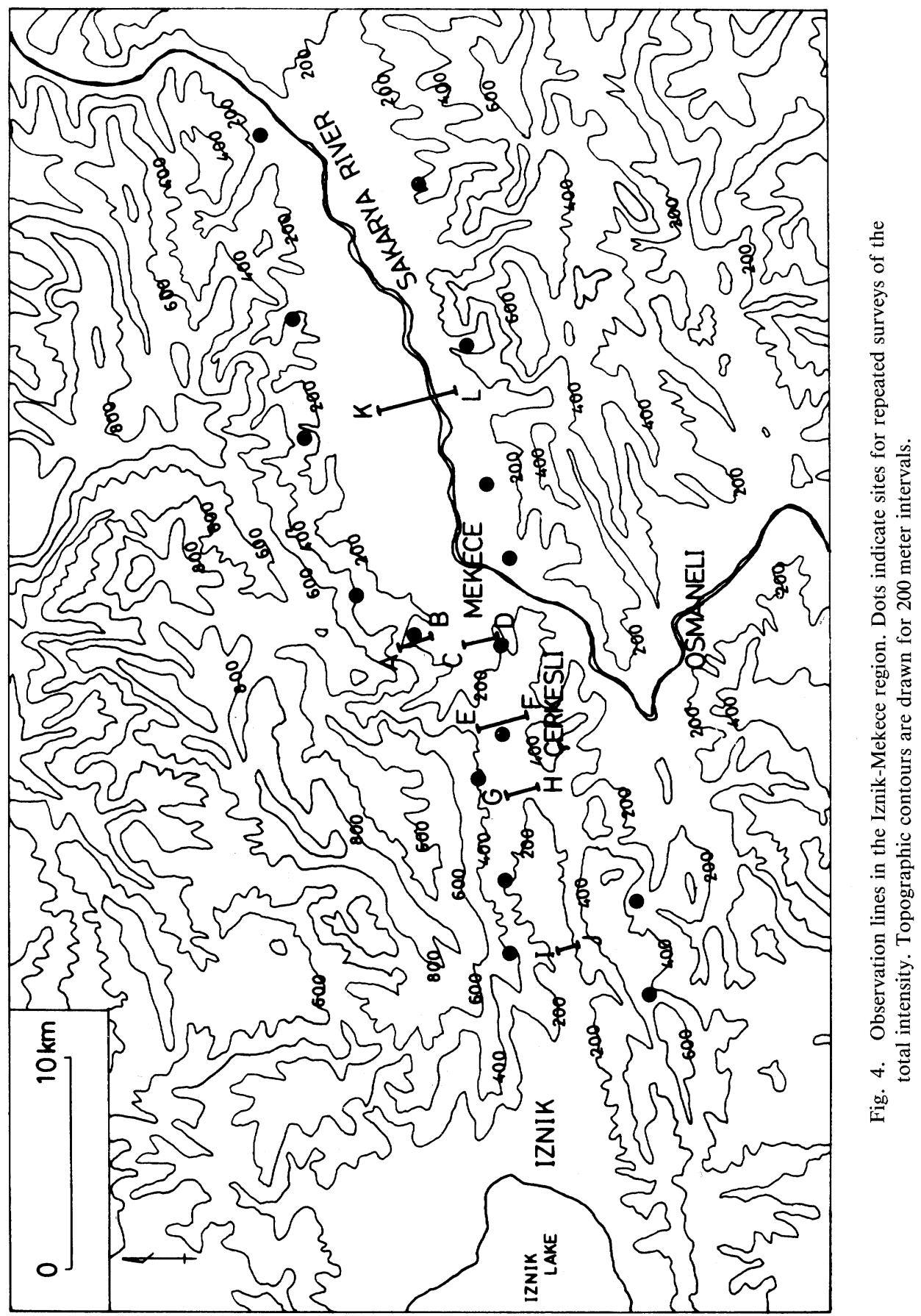




\section{MEKECE NO. 2}

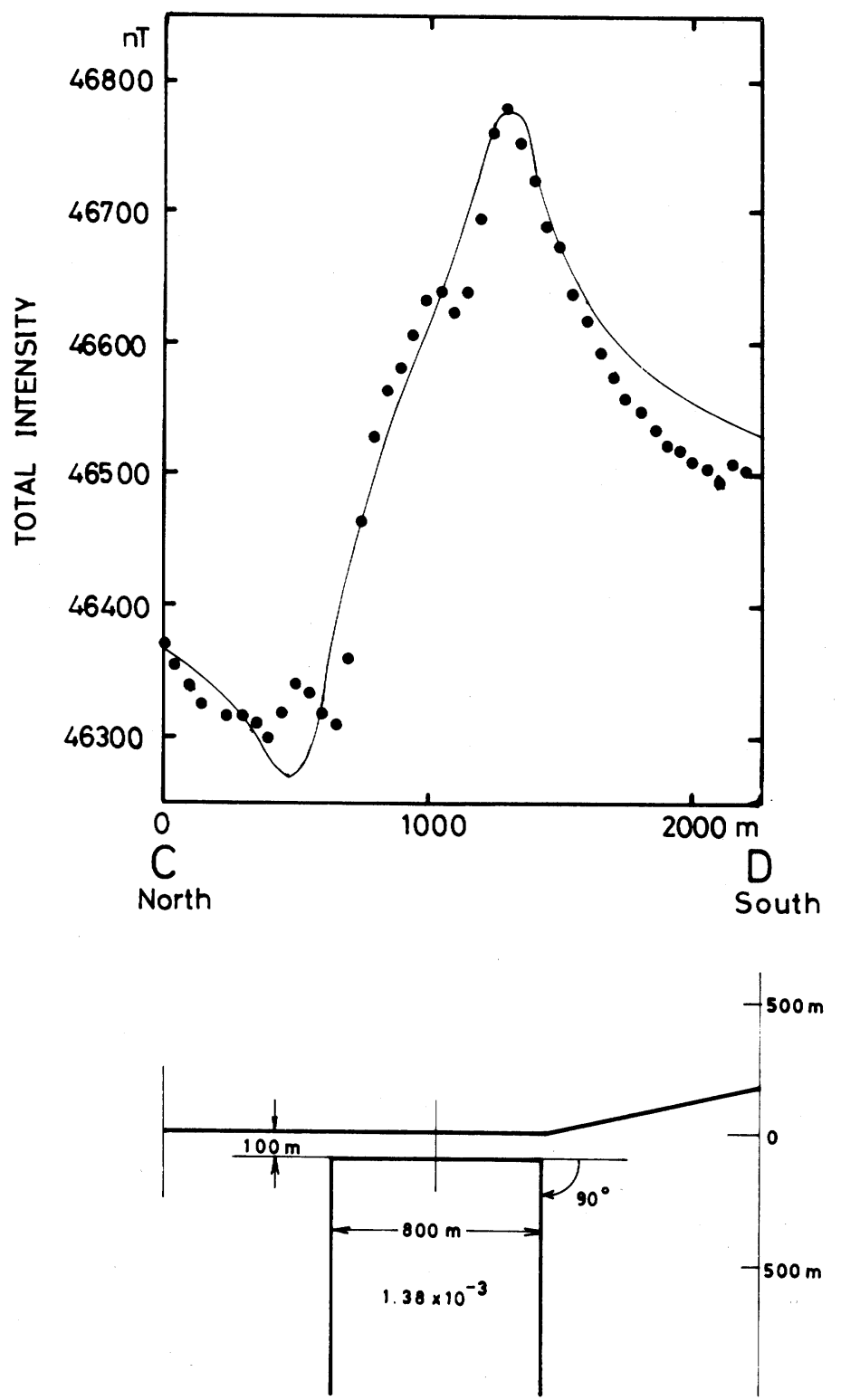

Fig. 5. Result of calculation for the initial model. Dots show the observation data. 
MEKECE NO. 2

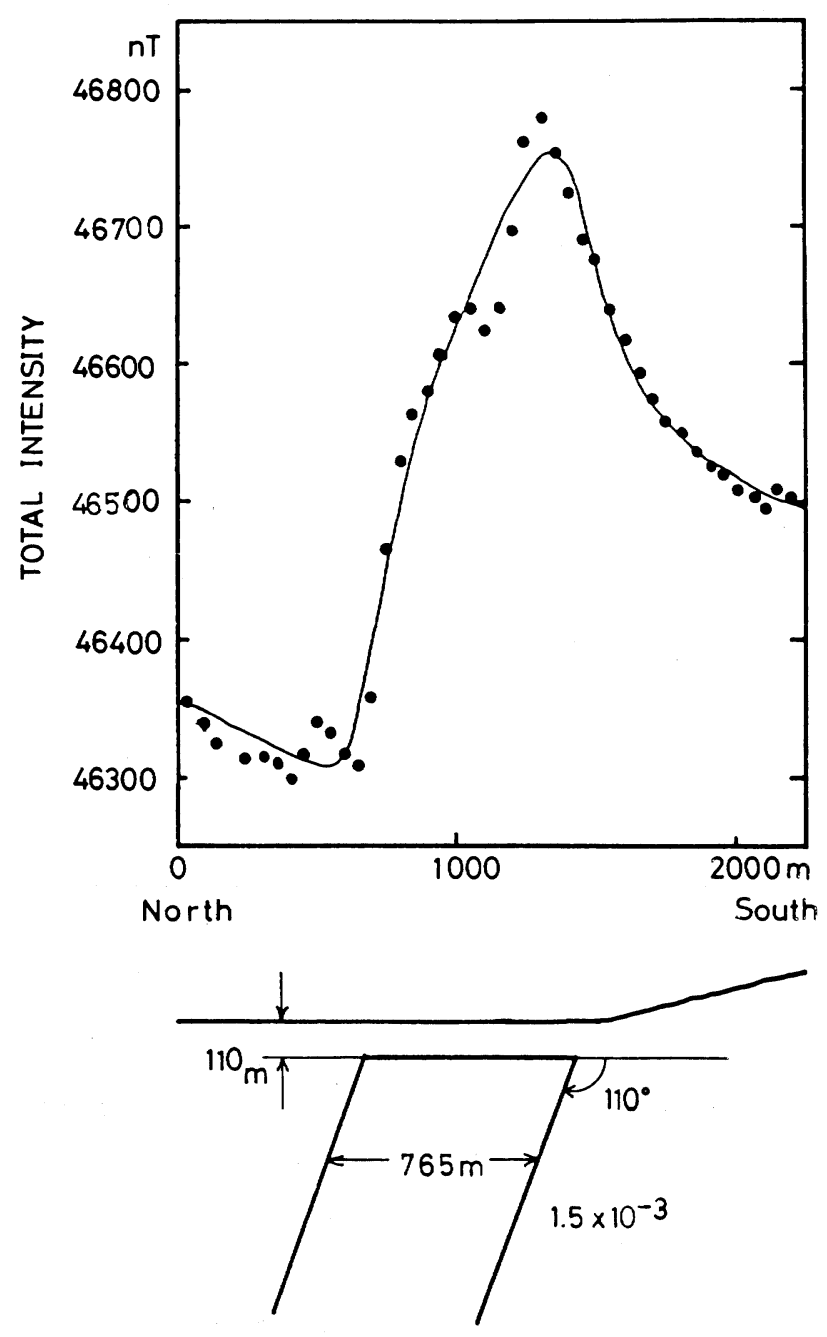

Fig. 6. Result of inversion for the Mekece data. 


\section{ÇERKESLI}

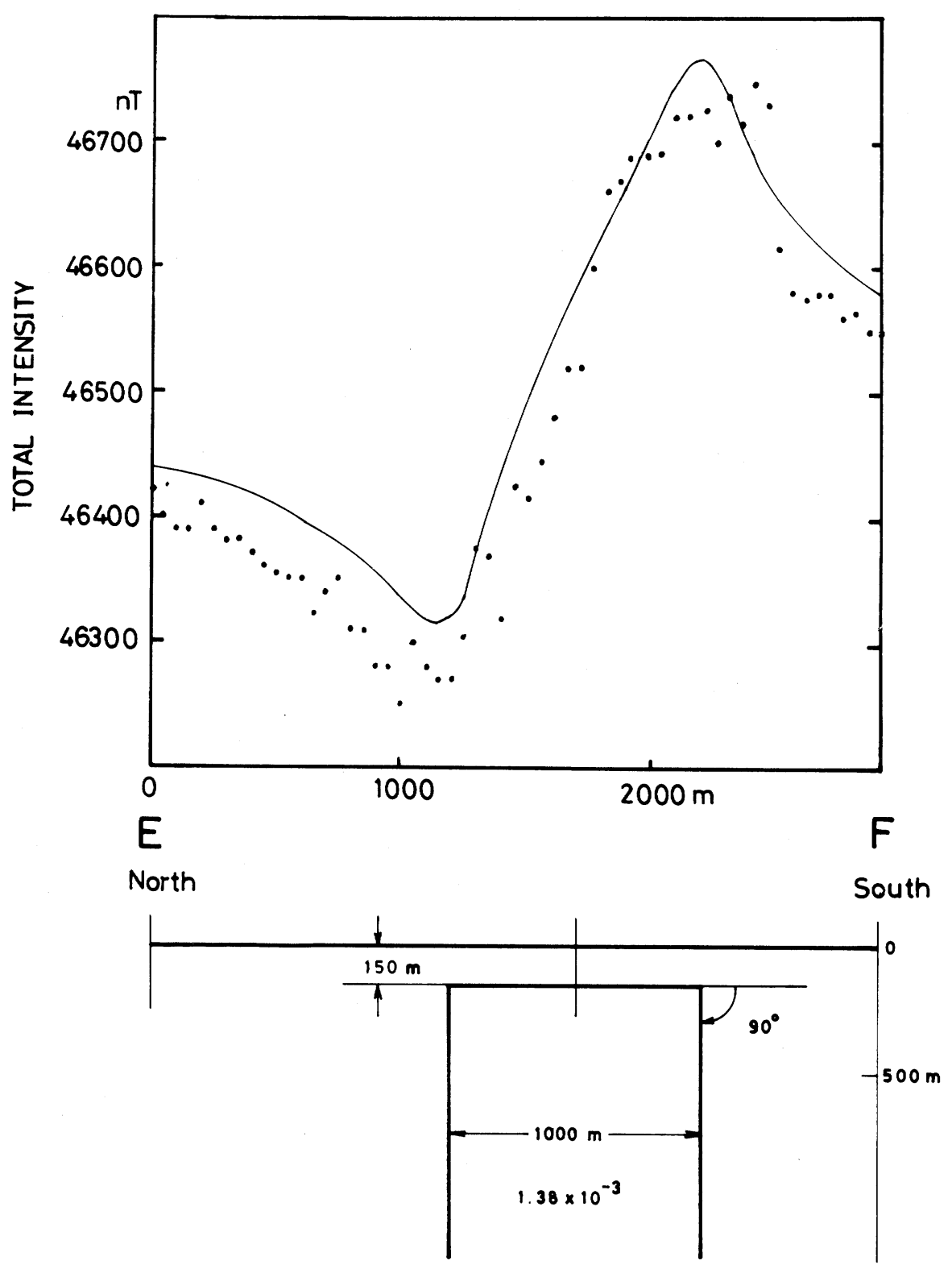

Fig. 7. Result of calculation for the initial model. 


\section{ÇERKESLI}
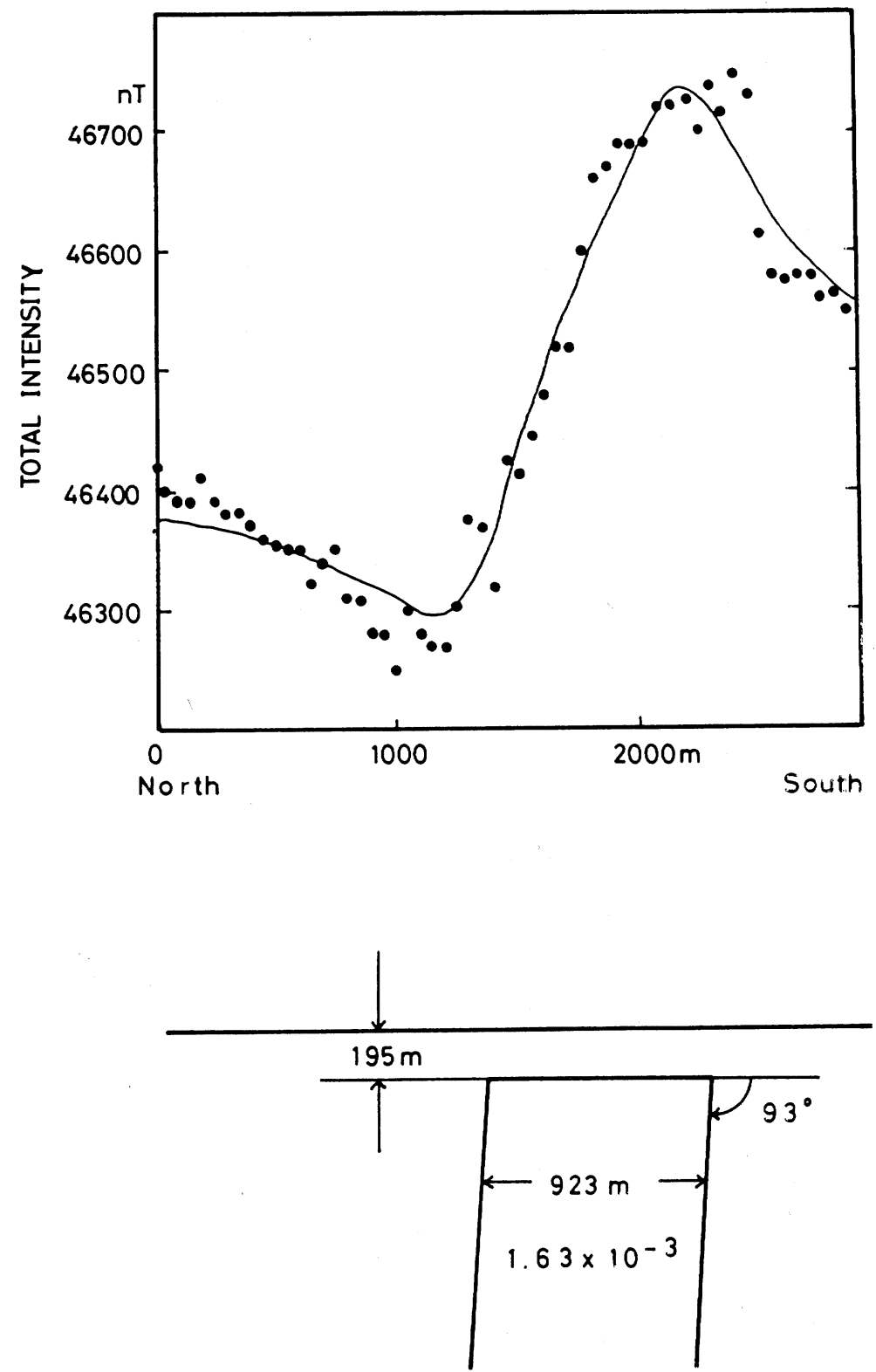

Fig. 8. Result of inversion for the Çerkesli data. 


\section{ÇERKESLI}

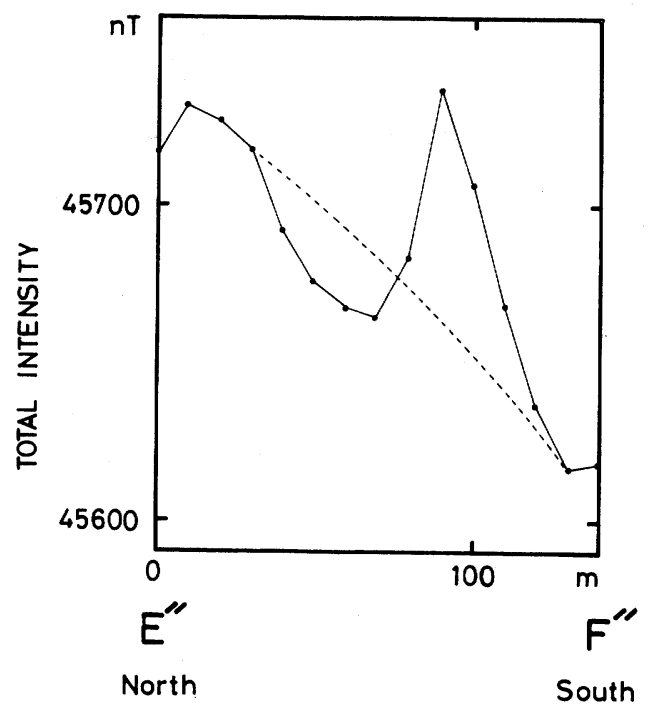

(a)

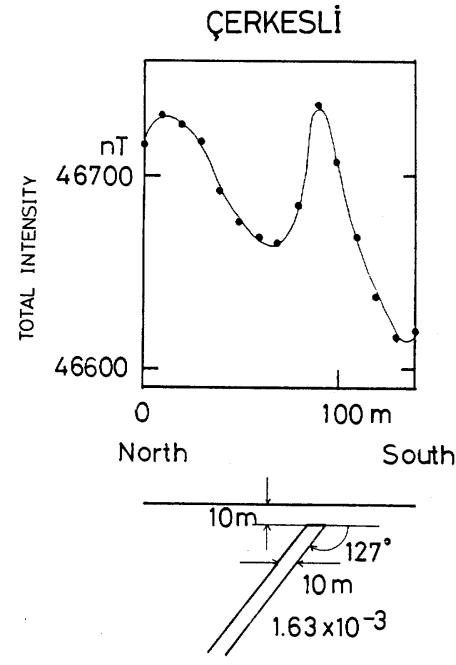

(b)

Fig. 9. (a) Total intensity data showing a local anomaly superposed on a regional trend, as represented by a dashed line, at Çerkesli. (b) Result of calculation for the thin and shallow dike which may be a branch from the main dike. 
Figure 10 shows the geomagnetic total intensity at Çardak. An anomalous total intensity amounting to $100 \mathrm{nT}$ or so is found. The result of calculation is also shown in Fig. 10. Rms error of the model which can best explain this anomaly is about $4 \mathrm{nT}$. It was expected that the dike exists at a considerable depth because the peak to peak amplitude of $100 \mathrm{nT}$ is smaller than those at Mekece and Çerkesli. As expected, the dike exists at a depth of about $800 \mathrm{~m}$. As this region is covered with thick sediments, we have no information on fault topography. In view of the existence of these dikes which seem to be identical because of their nearly equal magnetic susceptibility and thickness, it can be considered that the active fault exists again at the southern boundary of the dike here; at Mekece and Çerkesli, the southern boundries of the dikes coincided with the fault line.

However, an important problem has been left unsolved. The dip angle of this dike is 67 degrees, that is to say, the dike dips to the south, in contrast to those at

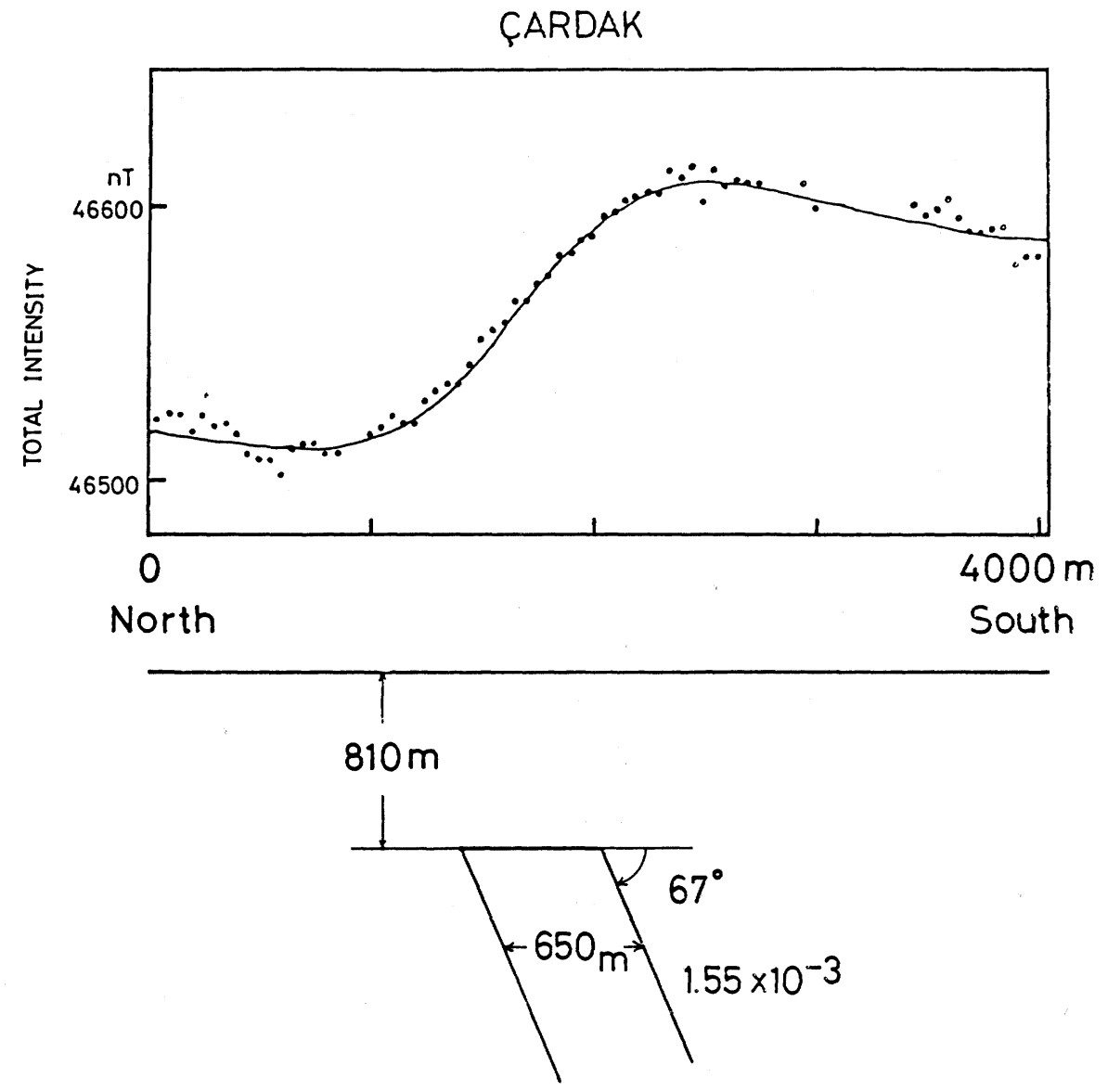

Fig. 10. Result of inversion for the Çardak data. 
Mekece and Çerkesli. This problem remains as the subject of future study.

\subsection{Analysis for Kaynarca}

Though we thought that magnetic anomalies would be observed everywhere along the fault line, no magnetic anomaly was observed in the region west of Çerkesli. However, further west, at Kaynarca, a magnetic anomaly was observed again.

Figure 11 shows a local anomaly amounting to nearly $400 \mathrm{nT}$. It is expected from the anomaly pattern that the dike dips to the south. Figure 11 also shows the result of model calculation. The cause of the southward dip and its shallow angle is unknown, and this problem is the subject of future study.

\subsection{Analysis for Ismetpasa No. 1}

Figure 12 shows a map of the observation region. Here, creep appears at the
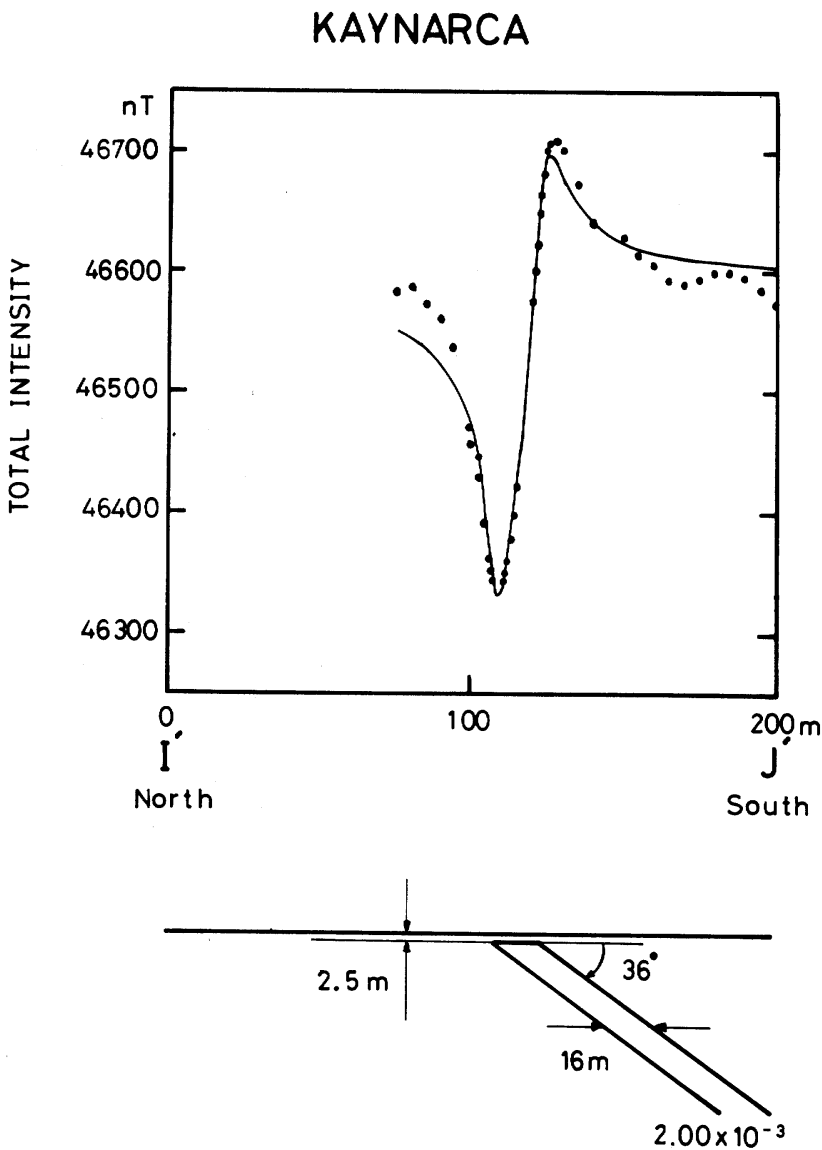

Fig. 11. Result of inversion for the Kaynarca data. 
surface and typical fault topography is seen. As marked in the map, this observation line is $500 \mathrm{~m}$ west of the place where creep appears at the surface and the topographic condition is not very suitable for observations, as is evident in Fig. 12.

A very local anomaly of total intensity amounting to $140 \mathrm{nT}$ was also found in this area. The model that best explains this anomaly is shown in Fig. 13. The location of the dike is identical to the creep zone. However, nothing anomalous was found at the other fault line.

\subsection{Analysis for Ismetpaşa No. 2}

This line is located several kilometers west of the Ismetpaşa No. 1 line. From topography four strike lines of fault were identified, as shown in Fig. 14. These strikes coincide very well with four positive peaks of total intensity as is clearly seen in Fig. 15 [and also with four zones of low resistivity, see HonkURA et al. (1985)].

Evidently no single dike can account for the observed magnetic anomaly and it would be reasonable to assume some sheets of dikes instead of a single dike. Then the inversion method which we used so far is no longer applicable, although the method may be extended for such a case. Hence, as in initial models for the inversion process, we searched for a model which can account for the observed data. One of the reasonable models is shown in Fig. 15. Although this model is by no means unique, as clearly implied by another model (WATANABE, 1984), it is in good harmony with the dike models at other profiles. We may further presume that each dike in Fig. 15 might even consist of some thinner dikes such as the one found at Ismetpaşa No. 1.

\section{Discussion and Concluding Remarks}

The magnetic anomalies as observed at Mekece, Çerkesli, and Çardak can be

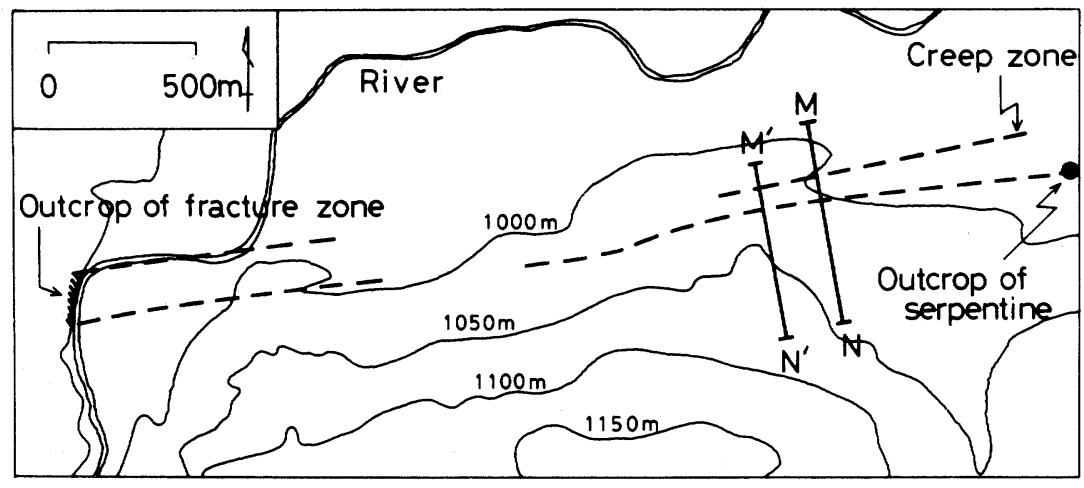

Fig. 12. Location of observation lines of Ismetpaşa No. 1. 
ISMETPAŞA NO.1

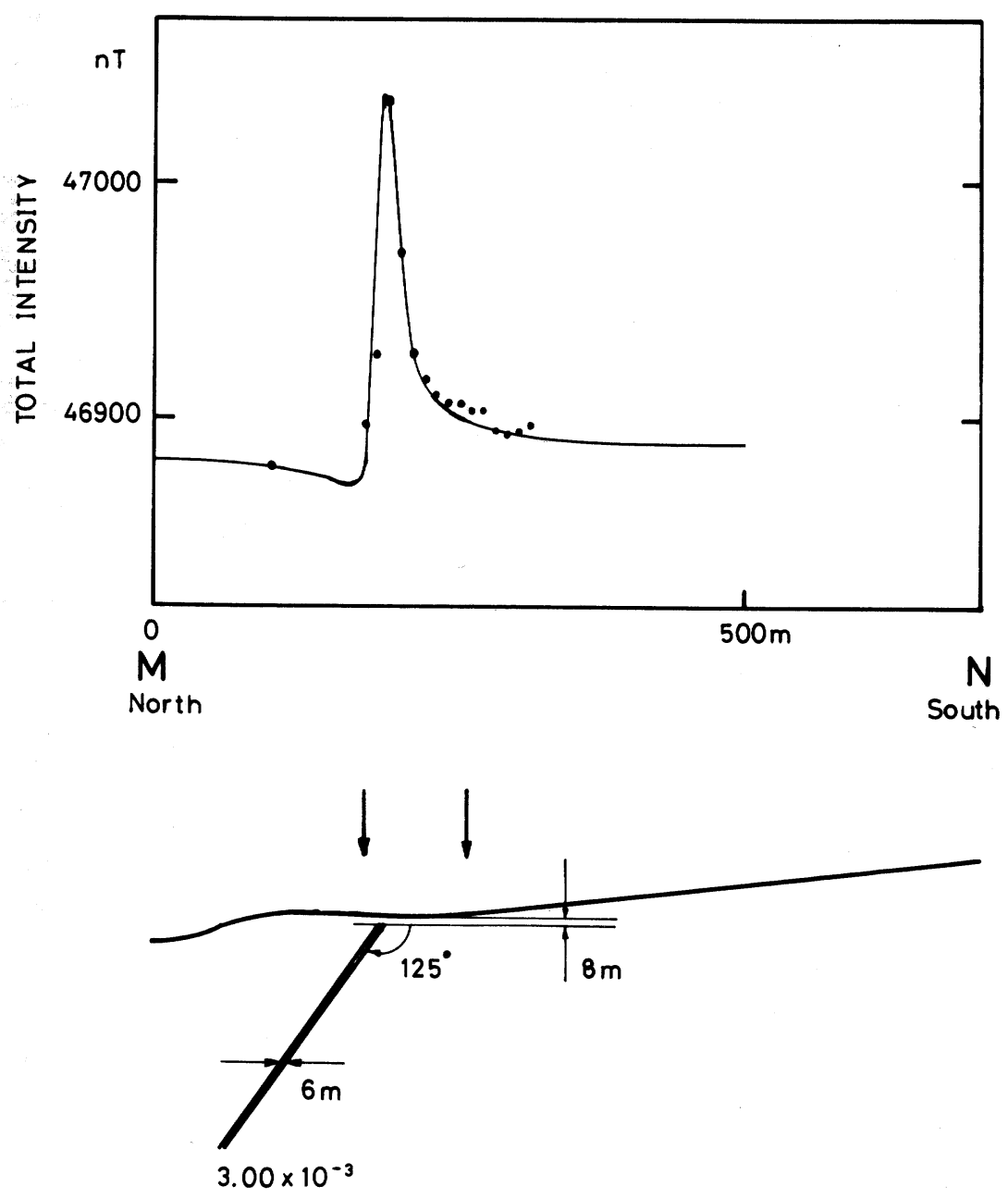

Fig. 13. Result of inversion for the Ismetapaşa No. 1 data.

explained by one dike elongated in the east-west direction (its magnetic susceptibility is $1.5 \times 10^{-3} \mathrm{emu} / \mathrm{cm}^{3}$ and its width ranges $600 \mathrm{~m}$ to $1000 \mathrm{~m}$ ), and the active fault line exists along the southern edge of this dike.

If the fault plane coincides with the southern wall of the dike, this fault may be regarded as a normal fault because the dike is not vertical but inclined northward and the southern side of the fault has been upheaved. In the case of normal faults, the stress field must be characterized by tension in the direction across the 


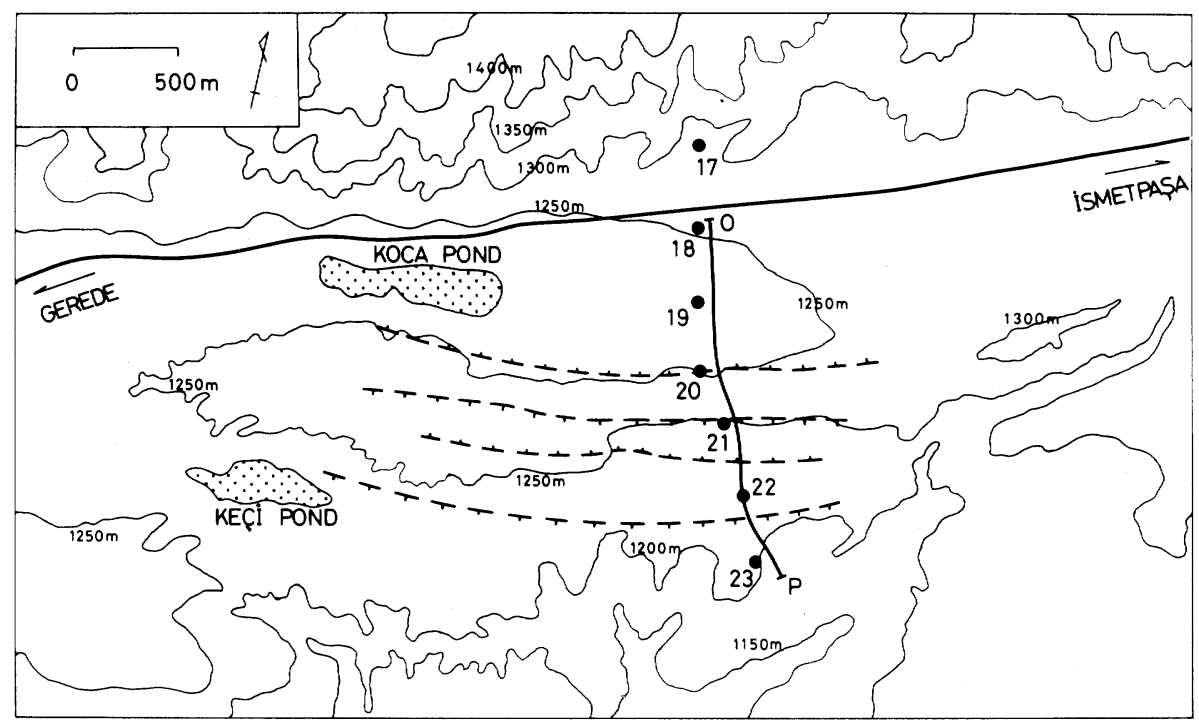

Fig. 14. Location of observation line of Ismetpaşa No. 2. Solid circles denote sites for magnetotelluric measurements.

fault. Then friction at the time of faulting would be expected to be weak, and the fault plane would be fractured little, which would result in a less developed fracture zone. Such a speculation seems to account for the fact that the low resistivity zone is not as extensive as expected (Honkura et al., in preparation). However, such normal faulting may be a rather secondary effect of primarily right-lateral movement of the North Anatolian Fault Zone.

In the Iznik-Mekece area a thick dike was found at a depth of $100 \mathrm{~m}$ or so, while some sheets of thinner dikes at shallow depth were suggested at the Ismetpaşa No. 2 profile. If such a group of dikes lies at depth, it would result in a simple magnetic anomaly at the earth's surface and the group of dikes may be interpreted as a single thick dike. Therefore, it is not unlikely that the thick dike as found in the Iznik-Mekece area is in fact a group of thinner dikes.

In any case, dike-like bodies seem to exist extensively along the North Anatolian Fault Zone and this feature can be used for searching for locations of active faults in such areas as sedimentary basins and shallow seas where surface topography provides little direct information on active fault locations.

Highly magnetic dike-like bodies may also be used as a local stress indicator if survey sites for the total intensity are appropriately distributed so that a change in magnetic susceptibility can be detected effectively as changes in the total intensity at many sites. In this sense, the distribution of survey sites as shown in Fig. 4 should be reconsidered, because magnetic anomalies had not been well studied when it was established. 
ISMETPASA NO.2
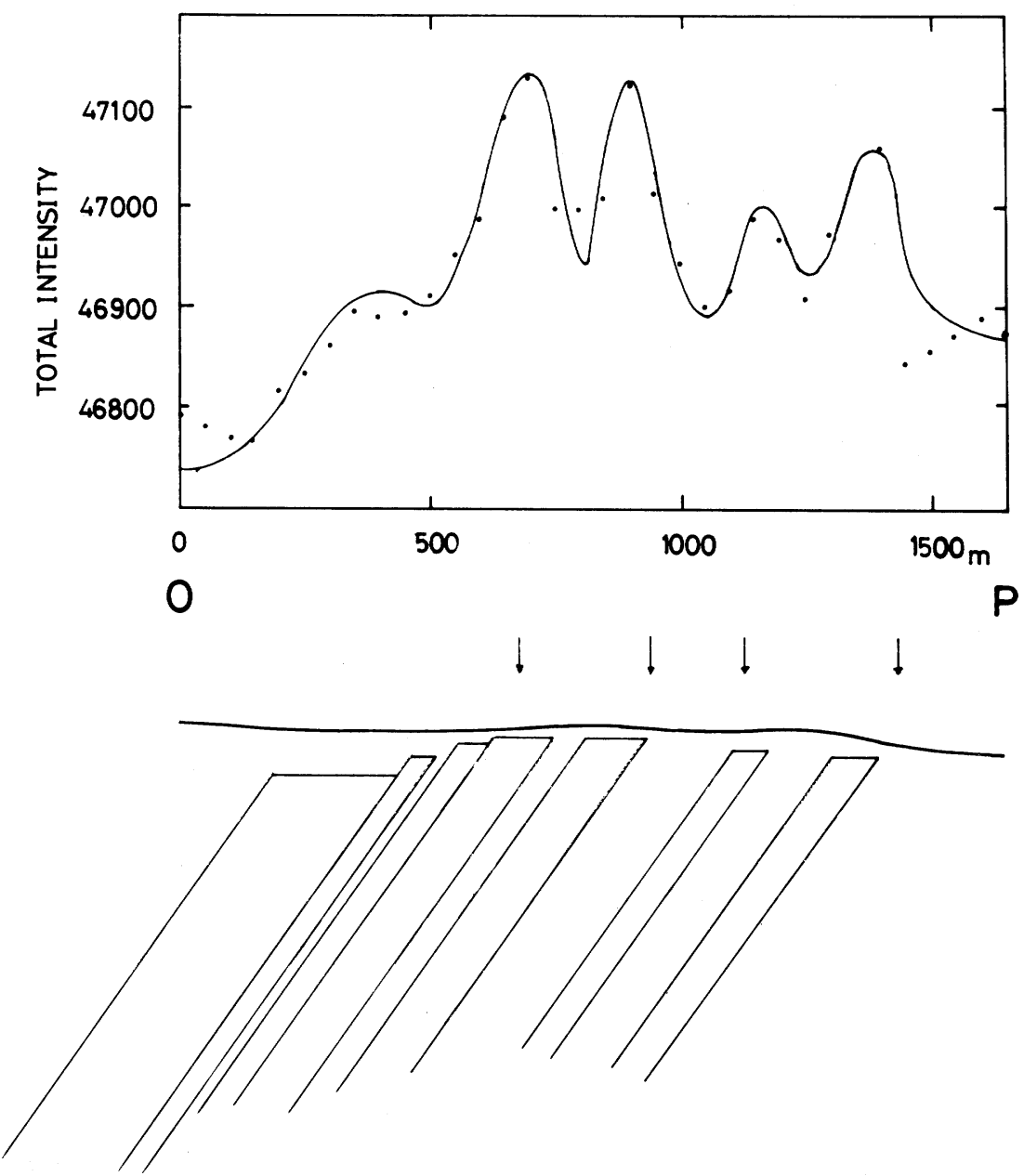

Fig. 15. A dike model which accounts for the observed data and the result of calculation along with the observed data at Ismetpaşa No. 2. The susceptibility of dikes is taken as $1.5 \times 10^{-3} \mathrm{emu} / \mathrm{cm}^{3}$. Arrows indicate locations of active fault lines.

The authors would like to thank the Earthquake Research Institute of Turkey and the Japan Society for Promotion of Science for support of this work. We also thank Prof. T. Rikitake and Prof. I. Özdoğan for their valuable help.

\section{REFERENCES}

Honkura, Y., A. M. Işikara, D. KolçAK, N. Orbay, S. SipahioǦlu, N. OhShiman, and H. TANaKa, 
Magnetic anomalies and low ground resistivity as possible indicators of active fault location: preliminary results of electric and magnetic observations from the western part of the North Anatolian Fault Zone, J. Geomag. Geoelectr., 37, 1985 (in press).

SipAHIOĞLU, S. and O. GÜNDOĞDU, Historical earthquake activity of the Iznik-Kastamonu segment of the NAFZ (before 1900), Bull. Earthq. Res. Inst. Turkey, 61-72, 1982.

ŞENGör, A. M. C., K. Burke, and J. F. Dewey, Tectonics of the North Anatolian Transform Fault, in Multidisciplinary Approach to Earthquake Prediction, edited by A. M. Isikara and A. Vogel, pp. 3-22, Friedr. Vieweg and Sohn, Braunschweig, 1982.

Soysal, H., D. KolçaK, and S. SipahioĞLU, Some aspects of the North Anatolian Fault Zone derived from the comparison of its instrumental data with historical information, in Multidisciplinary Approach to Earthquake Prediction, edited by A. M. Işikara and A. Vogel, pp. 223-238, Friedr. Vieweg and Sohn, Braunschweig, 1982.

Telford, W. M., L. P. Geldart, R. E. Sheriff, and D. A. Keys, Applied Geophysics, 860 pp., Cambridge Univ. Press, 1976.

Toksöz, M. N., A. F. Shakal, and A. J. Michael, Space-time migration of earthquakes along the North Anatolian Fault zone and seismic gaps, Pure Appl. Geophys., 117, 1258-1270, 1979.

Watanabe, N., Magnetic Anomalies at Active Faults, Graduation Thesis, Tokyo Inst. Tech., 42 pp., 1984.

Won, I. J., Application of Gauss's method to magnetic anomalies of dipping dikes, Geophysics, 46, 211-215, 1981. 